\title{
C2 Deficiency
}

\section{DEVELOPMENT OF LUPUS ERYTHEMATOSUS}

\author{
Noorbibi K. Day, H. Geiger, R. McLean, A. Michael, and \\ R. A. GooD \\ From the Departments of Pathology and Pediatrics, University of Minnesota \\ Hospitals, University of Minnesota, Minneapolis, Minnesota 55455
}

A B S T R A C T The study of serum from a patient with C2 deficiency is described. The patient had an episode of pneumococcal meningitis at 5 mo of age with seizures and transient hemiparesis and apparent purpuric skin lesions. He was first admitted to the University of Minnesota Hospitals at $10 \mathrm{yr}$ of age following the discovery of proteinuria accidentally by his mother. Since then he has been admitted repeatedly to this hospital with numerous clinical findings including arthralgia, recurrent abdominal pain, proteinuria, membranous nephropathy, malar butterfly rash, seizures, personality aberrations, and recurrent fever. In June 1971, the patient developed positive DNA and DNP antibodies and positive LE cells. When the $\mathrm{C}$ profile was studied before and after recognition of lupus, $\mathrm{C} 1 \mathrm{q}, \mathrm{C} 1 \mathrm{~s}$, and $\mathrm{C} 4$ dropped. $\mathrm{C} 3$ levels were elevated as were $\mathrm{C} 5, \mathrm{C} 6$, and $\mathrm{C} 7 . \mathrm{C} 3$ proactivator had been reduced in the patient even before he developed lupus. Also because of a traumatic renal biopsy leading to a perirenal hematoma, he required surgery and a blood transfusion. $1 \mathrm{~h}$ after blood transfusion, a C2 titer of 23 hemolytic units was detected. Almost immediately levels of $\mathrm{C} 3, \mathrm{C} 5, \mathrm{C} 6$, and $\mathrm{C} 7$ dropped. C8 and C9 remained elevated. The addition of $\mathrm{C} 2$ from normal blood permitted dramatic activation of $\mathrm{C} 3$.

These findings support the view that the rare deficiency in production of $\mathrm{C} 2$ predisposes to serious susceptibility to infection, vascular and mesenchymal disease as well as to renal disease and a lupus syndrome.

Dr. Day is an Established Investigator of the American Heart Association.

Dr. Geiger was supported by Deutscher Akademischer Austauschdienst. His present address is Universite Kinder Klinic, 69 Heidelberg, West Germany.

Dr. Good's present address is Sloan-Kettering Institute, Cancer Research Center, New York.

Received for publication 12 October 1972 and in revised form 5 March 1973.

\section{INTRODUCTION}

The association of complement deficiencies with recurrent infections and renal disease is gaining increasing importance. C1q (1-3), C1r (4-6), C1s (7), C2, and C3 deficient patients have been studied in our laboratories and also by other investigators (8-17). In most of these patients increased susceptibility to infections, vascular lesions, renal disease, and lupus-like syndromes have been observed. Pickering et al. (8) in these laboratories previously described a C2-deficient patient with chronic membranous glomerulonephritis. This patient has now developed clear evidence of lupus erythematosus (LE) ${ }^{1}$ and a comparative complement profile determined before and after recognition of lupus is reported in this study.

Briefly, this patient had an episode of pneumococcal meningitis at 5 mo of age with seizures and transient hemiparesis and apparent purpuric skin lesions. At $5 \mathrm{yr}$ he had frequent sore throats and since then has had numerous episodes of high fever without localizing symptoms. Other illnesses have included infectious mononucleosis at $7 \mathrm{yr}$ of age, atypical pneumonia at age 8 , and meningococcemia at $9 \mathrm{yr}$ of age. In addition, he has suffered throughout childhood with unexplained episodes of abdominal pains.

He was first admitted to the University of Minnesota Hospital in November 1967 at $10 \mathrm{yr}$ of age following the discovery that he had proteinuria. The mother had tested the patient's urine with Albustix since these were available to her because a younger sibling had had steroid-responsive idiopathic nephrotic syndrome. At this time he had spiking fevers, elevated sedimentation rate,

\footnotetext{
${ }_{1}^{1}$ Abbreviations used in this paper: FITC, fluorescein isothiocyanate; GMB, glomerular basement membrane; LE, lupus erythematosus.
} 
proteinuria, hematuria, and hypertension. The second admission was in May 1968 with a marked increase in severity of his disease. Prednisone and azathioprine were begun at this time and his urine became protein free. The third admission was in December 1969 because of increase in temperature and complaints of diffuse abdominal pains. A facial rash was noted at this time which became worse in sunlight. A kidney biopsy was repeated and showed chronic glomerulonephritis predominantly of membranous type. An extensive work-up for lupus erythematosus was negative. In 1970, he was admitted to the hospital on two occasions for abdominal pain, proteinuria, malar rash in butterfly distribution, seizures, personality aberrations, and recurrent fever. Following an appendectomy in January 1971, he had severe postoperative infection with high fevers which did not respond well to antibiotics. He was hospitalized three times in 1971 in Duluth, Minn. with seizures, high fevers, diarrhea, and high blood pressure. During each hospitalization, laboratory studies revealed an elevated rheumatoid factor but absence of anti-DNA antibodies of LE cells. In September 1971, the patient developed positive DNP and anti-DNA antibodies in titers of $1: 16$ and $1: 4$, respectively, and $L E$ cells were also demonstrable. Determination of complement and $\mathrm{C}$ components were undertaken and a comparative study of values obtained before and after recognition of clinical and laboratory manifestations of lupus are presented in this manuscript. Also because of a traumatic renal biopsy leading to a perirenal hematoma he required emergency surgery and a blood transfusion was given. After he had been given blood containing $\mathrm{C} 2$, studies of $\mathrm{C}$ components revealed that $\mathrm{C} 3$ had been activated immediately. This led to clear evidence of activation of $\mathrm{C} 5, \mathrm{C} 6$, and $\mathrm{C} 7$. The levels of C8 and C9 remained the same. Changes in the clinical complement profile following this crucial transfusion are reported in this study. With azathioprine and prednisone therapy, the patient has improved clinically. LE cells and antinuclear factors have disappeared from the blood, joint and abdominal pains have abated, and the renal disease remains stable.

\section{METHODS}

Buffers for $C$ assays. The disodium salt of ethylene diamine tetracetic acid (EDTA) reagent grade $\mathrm{Na}_{2} \mathrm{H}_{2}$ EDTA was titrated to $\mathrm{pH} 7.4$ at a stock concentration of $0.15 \mathrm{M}$. $\mathrm{Na}_{2} \mathrm{Mg}$ EDTA (Geigy Chemical Corp., Ardsley, N. Y.) was titrated to $\mathrm{pH} 7.4$ at a stock concentration of $0.15 \mathrm{M}$. Gelatin veronal buffer and glucose gelatin veronal buffer with and without $\mathrm{Ca}^{++}$and $\mathrm{Mg}^{++}\left(\mathrm{GGV}^{++}, \mathrm{GGV}^{--}\right.$) were prepared as described previously (18).

Serum. Blood was allowed to clot for $1 \mathrm{~h}$ at room temperature. The serum was removed after centrifugation at $40^{\circ} \mathrm{C}$, aliquoted, and stored at $-70^{\circ} \mathrm{C}$ until used.

Guinea pig C2. Partially purified C2 was prepared from guinea pig serum (Texas Biological Laboratory, Inc., Ft.
Worth, Tex.) according to the method described by Nelson, Jensen, Gigli, and Tamura (19).

$E A C 1, E A C 1,4$, and $E A C 4$. Cell intermediates with $\mathrm{C1}$ were prepared according to the methods described previously $(5,20)$.

Assays of total complement $\mathrm{CH} 5 \mathrm{O}$ and of the $\mathrm{C}$ components. Total $\mathrm{CH} 50$ was carried out as previously described (21). Functionally pure $C$ components for the assay of these components and EAClgp-7 HU for use in assay of C8 and C9 were obtained from Cordis Laboratories (Miami, Fla.) and the assays were carried out according to the method described by Nelson et al. (19). The experimental error of the $C$ components 1-9 ranged between 5 and $10 \%$. Immunochemical assays of these components $\mathrm{Clq}, \mathrm{Cls}$, and $\mathrm{C} 3 \mathrm{PA}$ were carried out by the Mancini technique $^{2}(22)$.

Immunofluorescent and light microscopy studies. Tissue was obtained by kidney biopsy over a period of $5 \mathrm{yr}$, and was studied by immunofluorescent and light microscopy as described previously (4). Monospecific antisera against human $\operatorname{IgG}, \operatorname{IgM}, \operatorname{IgA}, \mathrm{B} 1 \mathrm{c}$ globulin, $\mathrm{Clq}$, and properdin were tagged with fluorescein isothiocyanate (FITC) as described earlier $(23,24)$.

\section{RESULTS}

Table I presents observations on the total hemolytic complement and complement components observed in the patient's serum before and after recognizable lupus. As will be seen from the table, prior to development of clear clinical manifestations of lupus, the patient had a complement profile which showed unmeasurable $\mathrm{C} 2$ and moderate reduction of $\mathrm{C} 1$ and $\mathrm{C} 4$ accompanied by elevations of $\mathrm{C} 3, \mathrm{C} 5$, and $\mathrm{C} 9 . \mathrm{C} 6, \mathrm{C} 7$, and $\mathrm{C} 8$ were in the normal range. This profile was accompanied by progressive renal disease classified as membranous glomerulonephritis.

After he developed clear clinical evidence of lupus with the appearance of anti-DNA and DNP antibodies in the blood and a positive LE clot test, his complement profile changed in degree. Thus, it will be seen on the table that $\mathrm{C} 1$ and $\mathrm{C} 4$ dropped to very low levels, while C3 remained elevated and the remaining components did not show any significant change with the alteration of the clinical state.

Following a renal biopsy, the patient developed a perirenal hematoma and required transfusion with $1 \mathrm{U}$ of whole blood. Blood samples for complement assays were drawn serially and a complement profile of each sample was determined. Table II presents data on the total hemolytic complement and complement components of serum samples drawn during the $48 \mathrm{~h}$ after transfusion.

It can be seen from the table that when $\mathrm{C} 2$ had been provided in the transfused blood, the levels of C3 as measured by hemolytic assay dropped within $1 \mathrm{~h}$. Also at this time, levels of hemolytic activity of $\mathrm{C} 5, \mathrm{C} 6$, and $\mathrm{C7}$ components were found to be lower than those recorded

${ }^{2}$ Plates containing the above antisera were kindly provided by Dr. Hans Müller-Eberhard. 
TABLE I

Total Hemolytic C and C Components in Serum of C2-Deficient Patient Before and After Development of Recognizable Lupus Erythematosus*

\begin{tabular}{|c|c|c|c|c|c|c|c|c|c|}
\hline Patient & $\mathrm{CH} 50$ & C1 & $\mathrm{C} 4$ & $\mathrm{C} 3$ & $\mathrm{C} 5$ & $\mathrm{C} 6$ & $\mathrm{C} 7$ & C8 & C9 \\
\hline $\begin{array}{c}\text { Before lupus } \\
(12 / 2 / 70)\end{array}$ & $<10$ & $105,000 \downarrow \downarrow$ & $68,334 \downarrow$ & $4,050 \uparrow \uparrow$ & $4,800 \uparrow$ & 5,440 & 4,160 & 61,125 & $24,375 \uparrow$ \\
\hline $\begin{array}{l}\text { After lupus } \\
\qquad(10 / 21 / 71)\end{array}$ & $<10$ & $34,000 \downarrow \downarrow$ & $18,200 \downarrow \downarrow$ & $4,870 \uparrow \uparrow$ & $5,200 \uparrow \uparrow$ & 5,760 & 4,160 & 68,850 & $28,000 \uparrow \uparrow$ \\
\hline \multicolumn{10}{|l|}{ Normal } \\
\hline $\bar{X}$ & 45 & 430,000 & 246,000 & 2,600 & 3,415 & 6,150 & 5,529 & 65,889 & 15,795 \\
\hline 1S & $37-53$ & $\begin{array}{l}286,000- \\
574,000\end{array}$ & $\begin{array}{l}144,500- \\
347,500\end{array}$ & $\begin{array}{l}2,068- \\
3,132\end{array}$ & $\begin{array}{l}2,595- \\
4,235\end{array}$ & $\begin{array}{l}5,059- \\
7,241\end{array}$ & $\begin{array}{l}4,094- \\
6,964\end{array}$ & $\begin{array}{l}46,311- \\
85,467\end{array}$ & $\begin{array}{l}9,946- \\
20,644\end{array}$ \\
\hline $2 \mathrm{~S}$ & $29-61$ & $\begin{array}{l}145,000- \\
721,000\end{array}$ & $\begin{array}{c}43,000- \\
449,000\end{array}$ & $\begin{array}{l}1,536- \\
3,664\end{array}$ & $\begin{array}{l}1,775- \\
5,055\end{array}$ & $\begin{array}{l}3,968- \\
8,332\end{array}$ & $\begin{array}{l}2,659- \\
8,399\end{array}$ & $\begin{array}{l}26,733- \\
105,045\end{array}$ & $\begin{array}{r}4,097- \\
27,493\end{array}$ \\
\hline
\end{tabular}

* Hemolytic C2 was not measurable; $\downarrow$ below first standard deviation; $\downarrow \downarrow$ below second standard deviation; $\uparrow$ above first standard deviation; $\uparrow \uparrow$ above second standard deviation; $\bar{X}$, mean value of 40 healthy adults; $1 \mathrm{~S}$ values representing first standard deviation; $2 \mathrm{~S}$, values representing second standard deviation.

before transfusion. The C3 levels returned gradually to pretransfusion values within $24 \mathrm{~h}$. Hemolytic values of C6 and C7, however, remained low for at least $48 \mathrm{~h}$ after the transfusion.

Presented in Table III are immunochemical determinations of $\mathrm{C} 1 \mathrm{q}, \mathrm{C} 1 \mathrm{~s}, \mathrm{C} 4, \mathrm{C} 3, \mathrm{C} 5, \mathrm{C} 6, \mathrm{C} 8, \mathrm{C} 9$, the $\mathrm{C} 3$ proactivator, and properdin of the patient's serum as observed before and after recognizable clinical lupus, following transfusion of blood and subsequent steroid treatment. It will be seen in the table that the C1q levels, which were lower than normal before development of lupus, dropped to extremely low levels with change in clinical state. Following the transfusion of whole blood, the concentration of $\mathrm{Clq}$ was increased where it has remained with minor fluctuations. The levels of $\mathrm{C} 1 \mathrm{~s}$ which had been lower than normal in the pre-lupus phase, were also reduced after he developed recognizable clinical lupus. These levels were not appreciably altered by transfusion. Levels of C4 were also low prior to development of clinical lupus. The concentration of this component dropped a little with the change in clinical state. The concentration of this component was increased after transfusion, but promptly returned to the pretransfusion low levels within $6 \mathrm{~h}$ after the transfusion. Immunochemical determination also revealed a paradoxical elevation of C3 like that which had been observed upon hemolytic analyses. Following transfusion a decline of concentrations of this component was observed followed by a return to the elevated concentration by $48 \mathrm{~h}$ after transfusion. The elevated levels of $\mathrm{C} 5$ and $\mathrm{C} 6$ observed before the appearance of clinical lupus persisted with the change in clinical state and no dramatic alterations in immunochemically determined concentrations of these components were noted after transfusion. C3 proactivator and properdin did not change dramatically.

The results of the immunofluorescent staining of the kidney biopsy and the period of time when therapy was administered to the patient are summarized in Table IV. As indicated in the table, from 1967 to 1970, the kidney biopsy tissues were stained with FITC-tagged antisera against $\mathrm{B} 1 \mathrm{c}$, IgG, fibrin, $\mathrm{IgA}$, and $\mathrm{Clq}$. The intensity of immunofluorescence is arbitrarily graded as $0,1+, 2+$, and $3+$. There was a clear demonstration of positive glomerular staining for $\operatorname{IgG}(2-3+), \operatorname{IgM}(3+)$ on one occasion, much weaker staining for $\mathrm{C} 3(0-2+)$, and on one biopsy $\mathrm{Clq}(3+)$ was demonstrable. Light micros-

TABLE II

Total Hemolytic C and C Components in Serum of a C2-Deficiency Patient After Blood Transfusion

\begin{tabular}{rcrccccccc}
\hline Time & C1 & \multicolumn{1}{c}{$\mathrm{C} 4$} & $\mathrm{C} 2$ & $\mathrm{C} 3$ & $\mathrm{C} 5$ & $\mathrm{C} 6$ & $\mathrm{C} 7$ & $\mathrm{C} 8$ & C9 \\
\hline 0 & $70,000 \downarrow \downarrow$ & $17,300 \downarrow \downarrow$ & $<5 \downarrow \downarrow$ & $4,860 \uparrow \uparrow$ & $5,200 \uparrow \uparrow$ & 5,760 & 4,160 & 61,125 & $24,375 \uparrow$ \\
1 & $43,000 \downarrow \downarrow$ & $6,800 \downarrow \downarrow$ & $23 \downarrow \downarrow$ & 2,994 & 2,880 & $3,960 \downarrow \downarrow$ & $3,770 \downarrow$ & 57,720 & $25,000 \uparrow$ \\
6 & $51,000 \downarrow \downarrow$ & $10,900 \downarrow \downarrow$ & $<5 \downarrow \downarrow$ & $3,330 \uparrow$ & 2,660 & $3,200 \downarrow \downarrow$ & $3,650 \downarrow$ & 68,400 & $28,049 \uparrow \uparrow$ \\
17 & $42,000 \downarrow \downarrow$ & $8,500 \downarrow \downarrow$ & $<5 \downarrow \downarrow$ & $4,070 \uparrow \uparrow$ & 2,800 & $3,840 \downarrow \downarrow$ & 4,290 & 42,180 & $23,709 \uparrow$ \\
48 & $37,000 \downarrow \downarrow$ & $11,200 \downarrow \downarrow$ & $<5 \downarrow \downarrow$ & $4,277 \uparrow \uparrow$ & $6,400 \uparrow \uparrow$ & $2,465 \downarrow \downarrow$ & $3,848 \downarrow$ & 57,000 & $26,220 \uparrow$ \\
\hline
\end{tabular}

See footnotes to Table I. 
TABLE III

Immunochemical Determinations by the Mancini Technique of the C2-Deficient Patient Before Evidence of Lupus, and After Development of Recognizable Lupus, Blood Transfusion, and Treatment with Steroids

\begin{tabular}{|c|c|c|c|c|c|c|c|c|c|c|}
\hline & $\mathrm{Cla}$ & $\mathrm{C} 1 \mathrm{~s}$ & $\mathrm{C} 4$ & $\mathrm{C} 3$ & $\mathrm{C} 5$ & C6 & $\mathrm{C} 8$ & C9 & C3PA & Properdin \\
\hline & \multicolumn{10}{|c|}{$m g / m l$} \\
\hline Before lupus & 67 & 149 & 72 & 1,170 & 110 & 151 & 66 & 189 & 156 & 161 \\
\hline With lupus & 5 & 81 & 66 & 1,356 & 110 & 181 & 60 & 261 & 132 & 124 \\
\hline \multicolumn{11}{|c|}{ After blood transfusion } \\
\hline $1 \mathrm{~h}$ & 70 & 63 & 204 & 1,082 & 104 & 181 & 66 & 261 & 161 & 82 \\
\hline $6 \mathrm{~h}$ & 79 & 69 & 98 & 969 & 104 & 192 & 66 & 261 & 168 & 82 \\
\hline $17 \mathrm{~h}$ & 70 & 64 & 96 & 960 & 104 & 162 & 60 & 261 & 157 & 78 \\
\hline $24 \mathrm{~h}$ & 61 & 55 & 96 & 885 & 104 & 140 & 72 & 261 & 168 & 78 \\
\hline $48 \mathrm{~h}$ & 71 & 135 & 96 & 1,482 & 110 & 175 & 81 & 261 & 240 & 82 \\
\hline After treatment & 79 & 95 & 42 & 1,197 & 89 & 144 & & 165 & 128 & ND \\
\hline Normal & 208 & 138 & 134 & 1,200 & 77 & 116 & 54 & 150 & 237 & $107 \pm 27$ \\
\hline
\end{tabular}

Dates of sera used for immunochemical determinations were: before recognition of lupus $12 / 2 / 70$; after recognition of lupus $10 / 21 / 71$; after blood transfusion $10 / 22 / 71$.

copy of the renal tissue at this period revealed thickening of glomerular basement membrane (GBM), minimal mesangial proliferation, and normal tubules. The patient was not on therapy when the kidney biopsy was obtained in 1967. In 1968, he had been on prednisone, $40 \mathrm{mg}$ every 2nd day, and azathioprine daily. As he developed leukopenia, the azathioprine was given sporadically for a few months but was again continued through 1970. Early in 1971 his therapy was discontinued. Within a few months he developed recognizable lupus with positive LE cells, positive fluorescent antinuclear antibody and positive DNA, DNP, and anti-DNA, DNP antibodies. At this time light microscopy of kidney tissue revealed more prominent thickening of GBM, focal glomerular hyalini- zation, mild mesangial proliferation, and focal areas of tubular atrophy and interstitial fibrosis. Studies of the kidney biopsy by immunofluorescence also indicated a dramatic increase of intensity of $\mathrm{B} 1 \mathrm{c}$ in the glomerulus. At this time antisera against properdin was also available and this component was clearly present. $\operatorname{IgM}, \operatorname{IgA}$, and C1q were also demonstrable.

\section{DISCUSSION}

The association of glomerulonephritis-lupus-like syndrome, vascular disease, and recurrent infections in patients having deficiencies of single complement component has become evident. The recognition of lupus erythematosus in our patient who had long been known to have

TABLE IV

Summary of Studies by Immunofluorescence of the Patient's Kidney Tissue

\begin{tabular}{lccccccc}
\hline $\begin{array}{l}\text { Date of } \\
\text { kidney } \\
\text { biopsy }\end{array}$ & IgG & IgM & B1c & Fibrin & Properdin & IgA & C1q \\
\hline $10 / 24 / 67$ & $2-3+$ & 0 & $0-$ Trace & 0 & ND & $1-2+$ & ND \\
$10 / 1 / 68$ & $3+$ & ND & $1-2+$ & 0 & ND & ND & $3+$ \\
$12 / 19 / 69$ & $3+$ & ND & $0-$ Trace & ND & ND & ND & 0 -Trace \\
$12 / 8 / 70$ & $1+$ & $3+$ & 0 & 0 & ND & ND & 0 \\
$10 / 1 / 71$ & $3+$ & $3+$ & $3+$ & Trace & $2+$ & $3+$ & $3+$ \\
$10 / 11 / 71$ & $2-3+$ & $3+$ & $3+$ & 0 & $2+$ & $2+$ & $3+$ \\
Skin & 0 & 0 & 0 & 0 & 0 & 0 & 0 \\
\hline
\end{tabular}

Intermittent prednisone and azathioprine was started in October 1968 and discontinued in January 1971. No treatment was given for a period of $10 \mathrm{mo}(1 / 71$ to $10 / 71)$. Prednisone and azathioprine were restarted on October 25, 1971.

The intensity of immunofluorescence is arbitrarily graded as 0 , trace, $1+, 2+$, and $3+$. Tissues which were positive by immunofluorescence had nodular deposits along the glomerular basement membrane (Fig. 1).

$\mathrm{ND}$, not done. 
an extreme deficiency of $\mathrm{C} 2$, associated with membranous glomerulonephritis, supports the view that C-deficient patients may be as crucial to understanding the role of the normal complement system in the body economy as are patients with primary immunodeficiencies to understanding the esssential function of the components of the specific immunity systems. Most interesting in our case was the change observed in the $C$ profile after clinical and laboratory evidence of lupus developed. With the recognition of lupus, the serum level of $\mathrm{Clq}, \mathrm{Cl}$, and $\mathrm{C} 4$ dropped. At this time $\mathrm{C} 3$ levels were elevated as were C5, C6, and C7. This complement profile stands in contrast to those generally observed in serum of patients with lupus in which all $\mathrm{C}$ components up to $\mathrm{C} 7$ are depressed. This finding might be explained in one of two ways. Because of the deficiency of $\mathrm{C} 2, \mathrm{C} 3$ and later components cannot be activated by the primary pathway so that even with utilization of the alternate pathway, normal synthesis of C3 can keep up, or even exceed demands. Alternatively, the rate of synthesis of C3 might be very high as an acute phase function and synthesis could then exceed the utilization at normal levels. Further analysis of the catabolism of $\mathrm{C} 3$ becomes most important.

It is provocative that the $\mathrm{C} 3$ proactivator had been reduced even before a laboratory diagnosis of lupus could be made. This could account for the recurrent infections in this patient. Root et al. (25) have demonstrated that their guinea pigs deficient in C4 appear to be in good health under laboratory conditions. This may be a reflection of the role of the alternate pathway in host resistance to bacterial infections. In our patient, after recognizable lupus, the kidney biopsy showed an intensive staining of C3 by immunofluorescence which had previously been only weakly positive. Properdin and $\operatorname{IgA}$ were also present in the glomerular capillary loops. These findings suggest that the alternate pathway is indeed being engaged even though C3, C5, and C6 levels remain high.

These observations suggest that in lupus both the classical pathway of complement activation, and the alternate pathway can be activated by the patient's serum. Evidence from studies of Agnello, de Bracco, and Kunkel (13) are consonant with this finding. In the absence of $\mathrm{C} 2$, the so-called alternate pathway might be expected to be active. If $\mathrm{C} 2$ were present, utilization of the primary pathway would then be anticipated.

This view is consonant with our observations of changes in the $\mathrm{C}$ profile after blood transfusion in this patient. $1 \mathrm{~h}$ after a blood transfusion, a C2 titer of 23 hemolytic units was detected. Although this is still a low level, this was the first time $\mathrm{C} 2$ had ever been detectable in the patient's serum. Almost immediately, levels of C3, C5, C6, and C7 dropped. C8 and C9 remained elevated. The latter finding is of interest in light of Ruddy's report that C9 levels are elevated in lupus (26). It seems

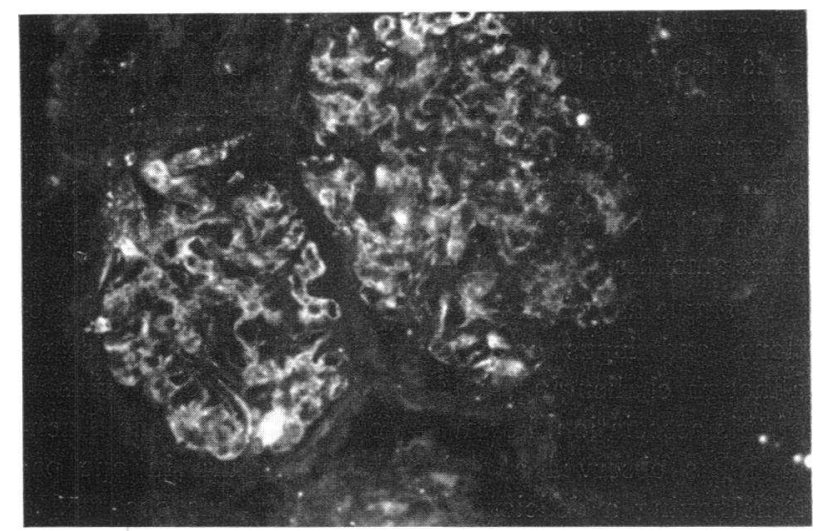

FIGLRE 1 Direct immunofluorescent staining reaction of kidney tissue of patient with C2-deficiency with FITCtagged monospecific rabbit antihuman properdin antiserum. Granular deposition of properdin is present along the glomerular basement membrane of all the glomeruli examined (original magnification $\times 160$ ).

clear that addition of $\mathrm{C} 2$ from the normal blood permitted dramatic activation of the classical pathway which could not take place in the absence of C2. Over an $18 \mathrm{~h}$ period, the level of $\mathrm{C} 3$ gradually returned to the original levels while $\mathrm{C} 5$ and $\mathrm{C} 6$ remained low for a more prolonged period. This difference may reflect differences in rates of synthesis of $\mathrm{C} 3$ on the one hand, and C5 and C6 on the other.

The findings in this case further suggest that our patient who had a gross deficiency of $\mathrm{C} 2$, perhaps on a genetic basis, is unable normally to resist infection. This possibility is suggested by the clinical history of frequent fevers and sore throats of unknown etiology, meningitis early in life, wound infection after surgery, and an apparent infectious complication of mumps. As a consequence of such susceptibility, immunization against DNA and other autoantigens might occur more readily than in normals. Because of the congenital absence of $\mathrm{C} 2$, the complement system would be selectively driven by the alternate pathway. When $\mathrm{C} 2$ became available with transfusion, activation of the conventional or more efficient complement pathway occurred. A high level of rheumatoid factor in the blood could also reflect a continuing infection or recurrent infections. Perhaps the deficiency of the early component $\mathrm{C} 2$ opens the door to recurrent or persistent virus infections, a suggestion consistent with the failure of the fever to respond to antibiotics. The seizures, abdominal pain, and neurologic abnormalities from early life could reflect vascular injury, perhaps secondary to activation of the alternate complement pathway. The family history also is of concern. The maternal grandmother had had unexplained skin ulcers and a brother developed nephrosis. Although possibly fortuitous these associations should prompt a detailed family study 
of complement profiles. These studies will be carried out. It is also probable that the absence of $\mathrm{C} 2$ has been important in preventing more severe complement-mediated glomerular injury. Although histologic evidence of membranous nephropathy was present, proteinuria was always mild and C3 was detected on the glomeruli only in trace amounts.

A single association of $\mathrm{C} 2$ deficiency, increased infections, and lupus complicating existing renal disease, although challenging, could be fortuitous. One example of this association, however, does not stand alone. Lachman has observed a patient with purpura in one patient having a deficiency of $\mathrm{C} 2$, Leddy has observed a C2-deficient patient with a syndrome like dermatomyositis to occur, Osterland has observed a C2 deficient patient with lupus erythematosus to occur (personal communication), and Agnello et a1. have reported a C2 deficient patient who developed lupus (13). In contradistinction to our observation, the case by Agnello et al. showed no evidence of activation of the earlier complement components. Studies of the C3PA in their case would be of interest. It thus seems clear that the rare deficiency in production of $\mathrm{C} 2$ predisposes to serious susceptibility to infection, vascular and mesenchymal disease as well as to renal disease and a lupus syndrome. Similar susceptibilities to infection, renal disease, and a lupus-like syndrome associated with other deficiencies of early complement components indicates that this part of the complement system represents a most significant defense against the development of such disorders. Much investigation in the future is needed to clarify these provocative relationships.

\section{ACKNOWLEDGMENTS}

The authors are grateful to Dr. Hans J. Müller-Eberhard for providing us with Mancini plates containing antisera for our immunochemical determinations, to Dr. Jon Girard for collecting blood samples after transfusion from the patient, and to Mrs. Linda Schuveiller for her excellent technical assistance.

This work was aided by grants from The National Foundation-March of Dimes, U. S. Public Health Service (AI-08677, Ai-10,704), Special Virus Cancer Program (Contract 71-2261), Kidney Foundation of the Upper Midwest, American Heart Association, American Cancer Society, and The Jane Coffin Childs Memorial Fund for Medical Research.

\section{REFERENCES}

1. Gewurz, H., R. J. Pickering, C. L. Christian, R. Snyderman, S. E. Mergenhagen, and R. A. Good. 1968. Decreased $\mathrm{Clq}$ protein concentration and agglutinating activity in agammaglobulinemia syndromes: an inborn error reflected in the complement system. Clin. Exp. Immunol. 3: 437.

2. Gewurz, H., R. J. Pickering, and R. A. Good. 1968. Complement and complement component activities in dis- eases associated with repeated infections and malignancy. Int. Arch. Allergy Appl. Immunol. 33: 368.

3. Kohler, P. F., and H. J. Müller-Eberhard. 1969. Complement-immunoglobulin relation: deficiency of $\mathrm{Clq}$ associated with impaired IgG synthesis. Science (Wash. D. C.). $163: 474$.

4. Pickering, R. J., G. B. Naff, R. M. Stroud, R. A Good, and H. Gewurz. 1970. Deficiency of $\mathrm{Clr}$ in human serum. Effects of the structure and function of macromolecular Cl. J. Exp. Med. 131: 803.

5. Day, N. K., H. Geiger, R. Stroud, M. de Bracco, B. Moncada, D. Windhorst, and R. A. Good. 1972. Clr deficiency: an inborn error associated with cutaneous and renal disease. J. Clin. Invest. 51: 1102.

6. Moncada, B., N. K. Day, R. A. Good, and D. Windhorst. 1972. Lupus-erythematosus-like syndrome with a familial defect of complement. N. Engl. J. Med. 286: 689.

7. Pondman, K. W., J. W. Stoop, R. H. Cormane, and A. J. Hannema. 1968. Abnormal $\mathrm{Cl}$ in a patient with systemic lupus erythematosus. J. Immunol. 101: 811 .

8. Pickering, R. J., A. F. Michael, R. Herdman, R. A. Good, and H. Gewurz. 1971. The complement system in chronic glomerulonephritis: three newly associated aberrations. J. Pediatr. 78: 30.

9. Gewurz, H., R. J. Pickering, L. Muschel, S. E. Mergenhagen, and R. A. Good. 1966. Complement-dependent biologic functions in complement deficiency in man. 1966. Lancet. $2: 356$.

10. Silverstein, A. M. 1960. Essential hypocomplementemia : report of a case. Blood. 16: 1338.

11. Klemperer, M. R., H. C. Woodworth, F. S. Rosen, and K. F. Austen. 1966. Hereditary deficiency of the second component of complement (C2) in man. J. Clin. Invest. 45: 880 .

12. Cooper, N. R., R. ten Bensel, and P. F. Kohler. 1968. Studies of an additional kindred with hereditary deficiency of the second component of human complement C2) and description of a new method for the quantitation of C2. J. Immunol. 101: 1176.

13. Agnello, V., M. M. E. de Bracco, and H. G. Kunkel. 1972. Hereditary C2 deficiency with some manifestations of systemic lupus erythematosus. J. Immunol. 108: 837 .

14. Klemperer, M. R., K. F. Austen, and F. S. Rosen. 1967. Hereditary deficiency of the second component of complement (C2) in man; further observations on a second kindred. J. Immunol. 98: 72.

15. Ruddy, S., M. R. Klemperer, and F. S. Rosen. 1970. Hereditary deficiency of the second component of complement (C2) in man; correlation of $\mathrm{C} 2$ hemolytic activity with immunochemical measurements of $\mathrm{C} 3$ protein. Immunology. 18: 943.

16. Alper, C. A., and F. Rosen. 1971. Genetic aspects of the complement system. Adv. Immunol. 14: 251.

17. Alper, C. A., H. R. Colten, F. S. Rosen, A. R. Rabson, G. M. Macnab, and J. S. S. Gear. 1972. Homozygous deficiency of $\mathrm{C} 3$ in a patient with repeated infections. Lancet. 2: 1179.

18. Mayer, M. M. 1961. Procedure for titration of complement components with R1, R2, R3, and R4. In Experimental Immunochemistry. E. A. Kabat and M. M. Mayer, editors. Charles C Thomas, Publisher, Springfield, Ill. 163.

19. Nelson, R. A., Jr., J. Jensen, I. Gigli, and N. Tamura. 1966. Method for the separation, purification and mea- 
surement of hemolytic complement of nine components of hemolytic complement and guinea-pig serum. Immunochemistry. $3: 235$.

20. Borsos, T., and H. Rapp. 1967. Immune hemolysis: a simplified method for the preparation of EAC4 with guinea pig or with human complement. J. Immunol. 99: 263.

21. Day, N. K. B., R. J. Pickering, H. Gewurz, and R. A. Good. 1969. Ontogenetic development of the complement system. Immunology. 16: 319.

22. Mancini, J., A. O. Carbonara, and J. F. Heremans. 1965. Immunochemical quantitation of antigens by single radial immunodiffusion. Immunochemistry. 2: 235.

23. Michael, A. F., K. N. Drummond, R. A. Good, and
R. L. Vernier. 1966. Acute poststreptococcal glomerulonephritis: immune deposit disease. J. Clin. Invest. 45: 237.

24. Westburg, G. N., G. Naff, J. Boyer, and A. F. Michael. 1971. Glomerular deposition of properdin in acute glomerulonephritis with hypocomplementemia. J. Clin. Invest. $50: 642$.

25. Root, R. K., L. Ellman, and M. M. Frank. 1972. Bactericidal and opsonic properties of $\mathrm{C} 4$ deficient guinea pig serum. J. Immunol. 109: 477.

26. Ruddy, S., L. K. Everson, P. H. Shur, and K. F. Austen. 1971. Hemolytic assay of the 9th complement component: elevation and depletion in rheumatic disease. J. Exp. Med. $134: 259 \mathrm{~s}$. 